\title{
Multiple Cutaneous Metastases in the Chest from Prostatic Carcinoma
}

\author{
G. Pistone A. Pistone M. Aricò M.R. Bongiorno \\ Department of Dermatology, University of Palermo, Palermo, Italy
}

\section{Key Words}

Cutaneous metastases · Prostatic carcinoma - AE1:AE3 cytokeratin · Prostate-specific antigen . Prostate-specific acid phosphatase

\begin{abstract}
We report a case of multiple cutaneous metastases from prostate cancer. A 78-year-old man with an 8-year history of prostate cancer had multiple nodular lesions in the chest. Histologically, the lesion showed an abortive glandular lumina and tall columnar cells with abundant cytoplasm. Immunohistochemical staining for AE1:AE3 cytokeratin cocktail, prostate-specific antigen, and prostate-specific acid phosphatase was positive in tumor cells, confirming the diagnosis of cutaneous metastases from prostate cancer. We report this case because of the rarity of cutaneous metastases from prostatic adenocarcinoma in the chest region.
\end{abstract}

\section{Case Report}

We present a case of multiple cutaneous metastases from prostate carcinoma in the chest region. A 78-year-old man with an 8-year history of prostate cancer metastatic to the bone presented with a 6-month history of several asymptomatic skin nodules that appeared in the chest. Despite repeated urging by his physician, he had refused further urologic evaluation and treatment.

The nodules in the chest were up to $0.5-1 \mathrm{~cm}$ in size, pinkish, firm and dome-shaped with a smooth surface (fig. 1a, b and fig. 2a). Pertinent laboratory studies included a prostate-specific antigen (PSA) serum level of $180 \mathrm{ng} / \mathrm{l}$ (normal range $0-4 \mathrm{ng} / \mathrm{ml}$ ), which had risen by $70 \mathrm{ng} / \mathrm{ml}$ in the 8 months preceding his presentation with the skin lesion. A full blood count and chemistry profile were within normal limits.

A skin biopsy of an isolated nodule on the chest stained with hematoxylin and eosin showed monotonous sheets and small clusters of basophilic neoplastic cells filling the papillary dermis and diffusely permeating the reticular and deep dermis (fig. 2b). Microscop-

Maria Rita Bongiorno, MD

Department of Dermatology, University of Palermo

Via del Vespro 131

IT-90127 Palermo (Italy)

E-Mail mariarita.bongiorno@unipa.it 
ically, the lesion is characterized by some abortive glandular lumina and by tall columnar cells with abundant cytoplasm, which form a single or pseudostratified layer. The cytoplasm is often amphiphilic and occasionally clear, there is marked cytological atypia. The nuclei have an open vesicular chromatin with prominent nucleoli (fig. 2c).

Immunophenotypic studies were performed by DAKO EnVision ${ }^{\mathrm{TM}_{+}} / \mathrm{HRP}$ Kit, including positive and negative controls. The primary antibodies used in this study were: monoclonal antibody to cytokeratin clones AE1/AE3, isotype IgG1 (DAKO), anti-human prostatic acid phosphatase clone PASE/4LJ isotype IgG1 (DAKO), monoclonal PSA clone ER/PR8, and isotype IgG1 (DAKO). Immunophenotypic studies for metastatic lesions showed the tumor cells staining positively for AE1:AE3 cytokeratin cocktail (fig. 2d), PSA (fig. 2e), and prostatespecific acid phosphatase (PSAP; fig. 2f). Cells labeled by the antibody displayed a cytoplasmic staining pattern, confirming the diagnosis of cutaneous metastases from prostate cancer [1].

\section{Discussion}

Prostatic carcinoma is one of the major cancers in men. It is known that the progression of the disease is highly associated with metastasis to the bone, lung, liver and adrenal glands, and the lymph nodes, whereas skin metastasis is considered exceptional and accounts for fewer than $1 \%$ of cutaneous metastases [2], with less than 80 cases published in the literature $[3,4]$.

When prostate carcinoma metastasizes to the skin, the metastases usually appear as multiple or solitary asymptomatic nodules or papules in the suprapubic region, lower abdominal area, genitalia, and the anterior aspect of the thigh $[2,5,6]$. Less frequently, other sites of distant metastasis include the chest, abdomen, face, and scalp [7, 8], and may not have the typical nodular morphology. Occasionally, skin metastases appear as sclerodermoid lesions [9].

Methods of spread to the subcutaneous tissues include direct extension, dissemination through the lymphatic system, and embolization of blood vessels. In prostate cancer, the skin manifestations usually occur late.

Skin metastases from prostate cancer are an ominous finding and most patients die within 6 months. Only a few cases with distant metastasis to areas such as the scalp or chest wall have been reported [3].

In conclusion, we reported this case because of the rarity of cutaneous metastasis from prostatic adenocarcinoma in the chest region. Urologic skin metastases are most common from renal tumors, followed by those of the bladder and then the prostate. Their clinical appearance may mimic other common dermatologic disorders affecting patients with advanced malignancies. Definitive diagnosis requires an index of suspicion and skin biopsy.

\section{Disclosure Statement}

The authors have no conflicts of interest to disclose. 


\section{References}

1 Paner GP, Luthringer DJ, Amin MB: Best practice in diagnostic immunohistochemistry: prostate carcinoma and its mimics in needle core biopsies. Arch Pathol Lab Med 2008;132:1388-1396.

2 Duran EP, Paradela A, Farina MC: Cutaneous metastases from prostatic carcinoma. J Surg Oncol 1996;62:144-147.

3 Schwartz RA: Cutaneous metastatic disease. J Am Acad Dermatol 1995;33(2 Pt 1):161-182.

4 Lookingbill DP, Spangler N, Sexton FM: Skin involvement as the presenting sign of internal carcinoma. A retrospective study of 7,316 cancer patients. J Am Acad Dermatol 1990;22:19-26.

-5 Mueller TJ, Wu H, Greenberg RE, et al: Cutaneous metastases from genitourinary malignancies. Urology 2004;63:1021-1026.

6 Steinkraus V, Lange T, Abeck D, et al: Cutaneous metastases from carcinoma of the prostate. J Am Acad Dermatol 1994;31:665-666.

7 Mishra VC, Tindall SF: Case report - cutaneous metastasis from a primary transitional cell carcinoma of prostate. Int Urol Nephrol 2001;33:507.

-8 Paz-Ares L, Olivia E, Carey RW, Smith MR: Skin lesions in malignancy: case 2: skin metastases from prostate adenocarcinoma. J Clin Oncol 2001;19:2099-2100.

$\checkmark 9$ Pique-Duran E, Paradela A, Farina MC, et al: Cutaneous metastasis from prostatic carcinoma. J Surg Oncol 1996;62:144-147.
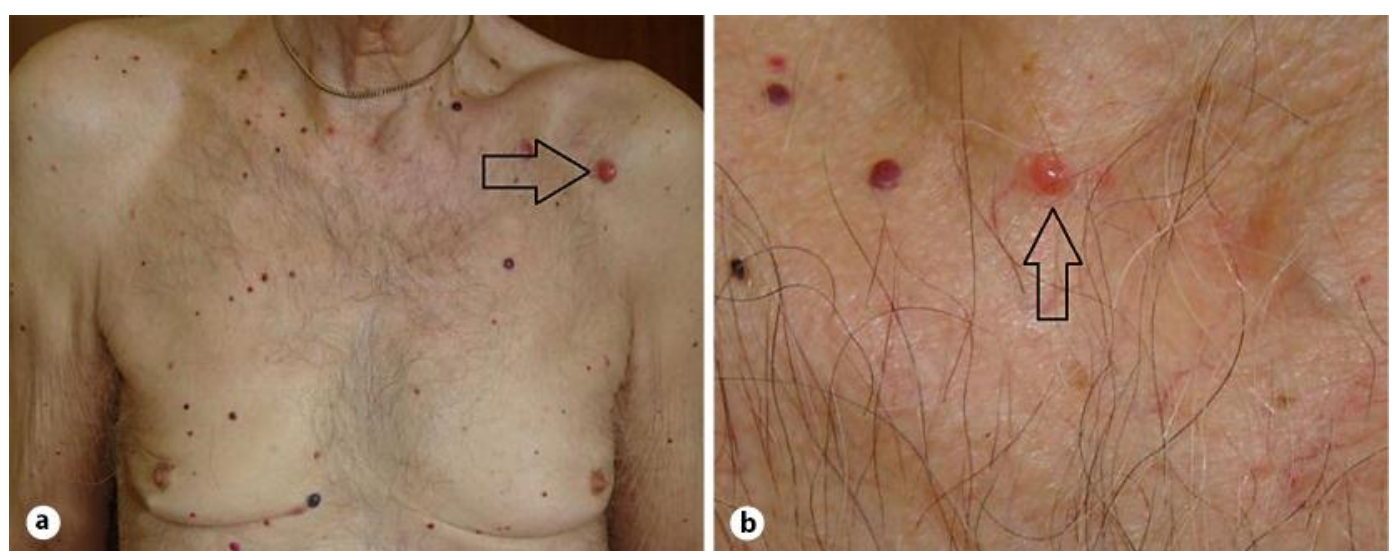

Fig. 1. a, b Clinical features: pinkish, firm, and dome-shaped nodules are seen in the chest. 


\section{Case Reports in Dermatology}
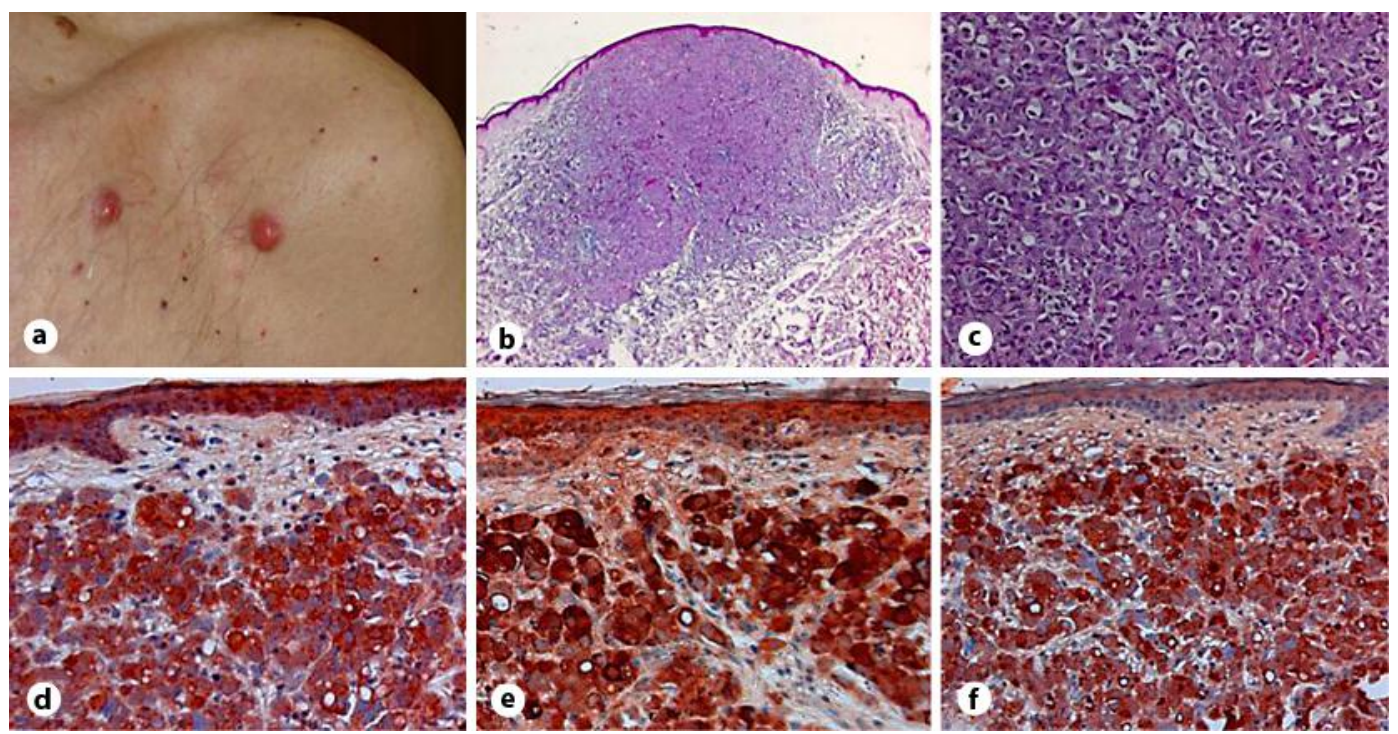

Fig. 2. a Clinical features: pinkish, firm, and dome-shaped nodules are seen in the chest. b Proliferation of neoplastic cells (HE: original magnification, 100x). c Atypical nuclei and clear cytoplasm and glandular structures in the dermis (HE: original magnification, 200x). d Positive staining of neoplastic cells with AE1:AE3 cytokeratin cocktail (original magnification, 320x). e Positive staining of neoplastic cells with prostatic acid phosphatase (original magnification, 320×). $f$ Positive staining of neoplastic cells with PSA (original magnification, 250x). 